\title{
S.I. for Dummies
}

\author{
Christian Tomaszewski, MD, FACMT
}

Hamad Medical Corporation and University of Pittsburgh Medical Center

As we were making rounds at a teaching hospital overlooking the Arabian Gulf, the nurse interrupted us to request intravenous dextrose for a 63-year-old patient with a random blood glucose level of $42 \mathrm{mg} / \mathrm{dl}$. On closer inspection, the patient did have an altered mental status, but the family claimed he ran out of insulin days earlier. Inspection of the glucose meter revealed an actual reading of $42 \mathrm{mmol} / \mathrm{L}$, in other words, an extraordinarily high glucose of $758 \mathrm{mg} / \mathrm{dl}$, more consistent with hyperosmolar coma than hypoglycemia. The patient obviously required fluids and insulin, not dextrose. The accompanying creatinine of $141 \mathrm{mmol} / \mathrm{L}$, or $1.6 \mathrm{mg} / \mathrm{dl}$ for our non-S.I. (International System of Units) users, confirmed years of renal ravage from his poorly treated diabetes.

These mistakes are probably not infrequent as the world fails to reach a common standard. Our glucose meter was made in the United States (U.S.), one of the few hold-out countries, which includes Liberia and Myamar, in adopting the international standard of the metric system. I must admit that I was using a cheat sheet that day, surreptitiously glancing down to make quick conversions to not let on that I was S.I. challenged. My formative medical years were in the U.S., and now as an S.I. illiterate, I was making rounds in a Middle East Hospital that used sensible S.I. units like the rest of the world.

Le Systeme International d'Unites (S.I. units) is used throughout most of the world except for the U.S. In 1960, the 11th General Conference of Weights and Measures adopted this as the practical system for units of measurement [1]. It is based on seven base units-meter, kilogram, second, ampere, mole, candela and Kelvin. Thanks to the Bureau International des Poids et Mesures, "deviations" such as Celsius for temperature, and minutes, hours, days, and years for time are acceptable. The S.I. system is commonly accepted in the international medical community and endorsed by the World Health Organization.

In 1975, the U.S. Congress passed the Metric Conversion Act, but still neither the metric system nor S.I. units are widely used [2]. Likewise, the U.S. medical community has considered converting to the metric based system of S.I. units [3]. Attempts as early as the 1980s to introduce such units into U.S. hospitals failed. Even the U.K., the progenitor of these ghastly English units, has made the switch in medicine and commerce, but not without a fight. In 2001, Steve Thoburn, the notorious "Metric Martyr," was convicted of selling bananas by the pound in deviance of the 1985 Weights and Measures Act, which stipulated that British customers be told the metric weight of loose food [4]. Such an enforcement approach may be the only way to get U.S. physicians to adopt S.I. units.

Reckoning comes for U.S. physicians typically when they submit a manuscript to a journal. According to the International Committee of Medical Journal Editors (ICJME), all measurements are to be reported in metric units and temperature in degrees Celsius [5]. This includes reporting of all hematological and clinical chemistry measurements in S.I. units. Even the New England Journal of Medicine in 1992 once considered enforcing S.I. units to the exclusion of "conventional" English units [6]. They quickly abandoned the idea because of the recalcitrance by American physicians to leave their comfort zone. In fact, an informal review of ten journals related to toxicology showed that almost half were not consistent in publishing laboratory findings in S.I. units.

Regardless of American physicians' comfort, the Journal of Medical Toxicology is an international Journal. We need to be able to speak the same language scientifically, especially when talking about laboratory units. In toxicology, S.I. units even make some calculations easier, such as the osmolar gap in the presence of toxic alcohols. But, more importantly, one consistent set of measurements may decrease error. The U.S. space agency, NASA, learned this the hard way, when in 1999 they lost a \$125 million Mars orbiter because one engineering team used metric units while another team used English units [7]. Although such dramatic mishaps have not been published in medicine, using the same language in medicine is important. And so far, the tide is against American physicians and in favor of S.I. units.

Keywords: S.I., International System of Units

Notes: There was no outside funding of any kind used for this study.

Corresponding Author: Christian Tomaszewski, MD, Hamad Medical Corporation and University of Pittsburgh Medical Center, P.O. Box 3050, Doha, Qatar. Email: Tomaszewskica2@upmc.edu 
Starting with future issues, the Journal of Medical Toxicology plans to enforce the use of S.I. units. As per the most recent ICMJE declaration, authors are to report laboratory information in both local and the International System of Units. For U.S. physicians this is a small inconvenience. But for the rest of the world, this is accepted medical practice. It allows an easy exchange of medical information throughout the world. With the increased reliance on published evidence-based medicine, this is one way to keep the metric flame alive. "Conversion lag" is one more contributor to U.S. students lagging in science, and American medicine will likewise suffer if we do not keep up with our international colleagues. As Thomas Friedman has pointed out in his recent nonfiction best seller, "the world is [indeed] flat" [8].

The author has no potential conflicts of interest to report.

\section{REFERENCES}

1. Bureau International des Poids et Mesures: The International System of Units (SI). $8^{\text {th }}$ edition 2006; Stedi Media, Paris; pp 93-180.
2. Taylor, B: Guide for the Use of the International System of Units (S.I). U.S. Department of Commerce National Institute of Standards and Technology Special Publication 911, 1995 edition. Washington D.C. pp 86.

3. Huth EJ. The American shift to medical SI units. Annals of Internal Medicine. 106(1):149-50, 1987.

4. Summers C: Will we ever go completely metric? BBC News Online. Sept 2, 2004 http://news.bbc.co.uk/1/hi/magazine/ 3934353.stm

5. International Committee of Medical Journal Editors: Uniform requirements for manuscripts submitted to biomedical journals. NEJM 1997; 336:309-315. http://www.icmje.org/ index.html

6. Watson T: NEJM restricts use of SI units. Nature 1992;359(6392):175.

7. Lloyd R: Metric mishap caused loss of NASA orbiter. September 30, 1999. http://www.cnn.com/TECH/space/9909/ 30/mars.metric.02

8. Friedman T: The World is Flat: A Brief History of the Twenty-First Century. 2005. Farrar, Starus and Giroux, New York; 304. 